\title{
BLUNTED GABA-MEDIATED INHIBITION WITHIN THE DORSOMEDIAL HYPOTHALAMUS POTENTIATES THE CARDIOVASCULAR RESPONSE TO EMOTIONAL STRESS IN RATS FED A HIGH-FAT DIET
}

\author{
A. R. ABREU, A. R. DE ABREU, L. T. SANTOS, \\ A. A. DE SOUZA, L. G. DA SILVA, Jr. \\ D. A. CHIANCA Jr. AND R. C. DE MENEZES * \\ Department of Biological Sciences, Institute of Exact and \\ Biological Sciences, Federal University of Ouro Preto, Ouro \\ Preto, MG, Brazil
}

\begin{abstract}
Rats fed a high-fat diet (HFD) present an exaggerated endocrine response to stress conditions, which, like obesity, show a high correlation with cardiovascular diseases. Meanwhile the GABAergic neurotransmission within the dorsomedial hypothalamus (DMH) is involved in the regulation of the physiological responses during emotional stress. Here we evaluated the influence of obesity, induced by a HFD, on the cardiovascular responses induced by air jet stress in rats, and the role of the GABAergic tonus within the DMH in these changes. Our results showed that consumption of a HFD ( $45 \% \mathrm{w} / \mathrm{w}$ fat) for 9 weeks induced obesity and increases in baseline mean arterial pressure (MAP) and heart rate (HR). Moreover, obesity potentiated stress responsiveness, evidenced by the greater changes in MAP and HR induced by stress in obese rats. The injection of muscimol into the DMH reduced the maximal increases in HR and MAP induced by stress in both groups; however, the reduction in the maximal increases in MAP in the HFD group was less pronounced. Moreover, the injection of muscimol into the DMH of obese rats was less effective in reducing the stress-induced tachycardia, since the HR attained the same levels at the end of the stress paradigm as after the vehicle injection. Injection of bicuculline into DMH induced increases in MAP and HR in both groups. Nevertheless, obesity shortened the tachycardic response to bicuculline injection. These data show that obesity potentiates the cardiovascular response to stress in rats due to an inefficient $\mathrm{GABA}_{\mathrm{A}}$-mediated inhibition within the DMH. (c) 2014 IBRO. Published by Elsevier Ltd. All rights reserved.
\end{abstract}

\footnotetext{
${ }^{*}$ Corresponding author. Address: Universidade Federal de Ouro Preto (UFOP), Instituto de Ciências Exatas e Biológicas, Departamento de Ciências Biológicas, Laboratório de Fisiologia Cardiovascular, Ouro Preto, MG 35400-000, Brazil. Tel: +55-31-3559-1721; fax: + 55-31-3559-1680.

E-mail addresses: alirriba@yahoo.com.br (A. R. Abreu), arrabreu @gmail.com (A. R. de Abreu), laugbatista@yahoo.com.br (L. T. Santos), alinearlindo.nut@gmail.com (A. A. de Souza), gonza gaufmg@gmail.com (L. G. da Silva Jr.), deochianca@gmail.com (D. A. Chianca Jr.), rodrigo.menezes@iceb.ufop.br (R. C. de Menezes).

${ }^{\dagger}$ Present address: Department of Basic Health Sciences, Federal University of Juiz de Fora, Governador Valadares, MG, Brazil.

Abbreviations: ACTH, adrenocorticotropic hormone; ANOVA, analysis of variance; $\mathrm{BMI}$, bicuculline methiodide; $\mathrm{DMH}$, dorsomedial hypothalamus; HFD, high-fat diet; HR, heart rate; MAP, mean arterial pressure; NPY, neuropeptide Y; PVN, hypothalamic paraventricular nucleus; SEM, standard error of the mean.
}

Key words: obesity, emotional stress, dorsomedial hypothalamus, GABA.

\section{INTRODUCTION}

Obesity, especially the visceral type, is associated with several diseases, especially in the cardiovascular system (Modan et al., 1985; Eckel, 1997). The sympathetic drive to skeletal muscles and kidneys is increased in obese patients (Alvarez et al., 2002; Kuniyoshi et al., 2003; Huggett et al., 2004). This increase in sympathetic activation has been considered a key factor in the development of obesity-related hypertension in these patients (Rumantir et al., 1999; Masuo et al., 2000), even though some authors have demonstrated that in humans the BP and heart rate (HR) response to mental stress was similar in lean and obese humans (Kuniyoshi et al., 2003).

In animal models, the correlation between hypertension, increased sympathetic activity and obesity can also be observed. For instance, the obese Zucker rats, which present a mutation in the leptin gene (inducing hyperphagia-induced obesity), have an increased renal sympathetic activity associated with hypertension (Morgan et al., 1995). In another study, animals fed a high-fat diet (HFD; $45 \%$ of the calories from fat) developed hypertension accompanied by an increase in the renal sympathetic activity (Nagae et al., 2009).

The increased sympathetic activity observed in obese animals could not only induce hypertension, but could also modify the cardiovascular responses to stress, given that the physiological responses to stress are also dependent on the sympathetic activation (see Fontes et al., 2011).

During emotional stress the central nervous system produces changes in various physiological variables aiming to increase survival (Clark et al., 1997). These are characterized by increases in the circulating adrenocorticotropic hormone (ACTH), mean arterial pressure (MAP), HR and temperature (Stotz-Potter et al., 1996a; Stotz-Potter et al., 1996b; de Menezes et al., 2008; Ootsuka et al., 2008). However, chronic exposure to stressful situations, leading to sustained alteration in MAP and HR, can result in cardiovascular diseases such as hypertension, cardiac arrhythmia and infarction (Amiragova, 1985; Leor et al., 1996; DiMicco et al., 2002).

It is well known that the dorsomedial hypothalamus $(\mathrm{DMH})$ neurons are essential to the integration of the 
physiological and behavioral responses to emotional stress (Soltis and DiMicco, 1991b; DiMicco et al., 2002; da Silva Jr et al., 2006). Importantly, the DMH neurons appear to be tonically inhibited by GABAergic tone. Disinhibition of this region by a local microinjection of $\mathrm{GABA}_{A}$ receptor antagonist induces increases in $H R$, MAP and ACTH in a pattern similar to the one observed during emotional stress (Shekhar and DiMicco, 1987; Fontes et al., 2001; da Silva et al., 2003; da Silva Jr et al., 2006; de Menezes et al., 2006).

Although obesity and emotional stress are major risk factors to cardiovascular diseases, few studies have examined if these variables can be integrated on the development of these diseases. Notably, it has been shown that obese Zucker rats present an exaggerated blood pressure response to stress, suggesting that obesity could have an influence over the cardiovascular reactivity to emotional stress (D'Angelo et al., 2006). Moreover, spontaneously hypertensive rats, fed a HFD, present a delayed recovery of the cardiovascular response induced by stress (Sedova et al., 2004).

In experiments performed in mice, Xin and colleagues, demonstrated that animals fed a HFD, which became obese, had an increased c-fos expression in the $\mathrm{DMH}$, suggesting an increased neuronal activity in this area (Xin et al., 2000). The neuronal over activity, during resting conditions, within the $\mathrm{DMH}$, in obese animals, could be an indicator that this nucleus could be more active during stress circumstances, which in turn, could lead to an exaggerated cardiovascular response to emotional stress. The activity of $\mathrm{DMH}$ neurons is regulated by a tonic GABAergic inhibitory input that controls an excitatory glutamatergic tonus (Soltis and DiMicco, 1991a). Moreover, during stress conditions this inhibitory input is lessened allowing the excitatory drive to stimulate the DMH neurons (Soltis and DiMicco, 1992).

Considering the potential role of obesity and emotional stress in the development of cardiovascular diseases, and the role of the Gabaergic tonus within the $\mathrm{DMH}$ in the regulation of the stress response, we intended to assess the impact of obesity on the Gabaergic function within the $\mathrm{DMH}$ and its influence over the reactivity to emotional stress in rats. Thus, the aim of the present study was to evaluate the cardiovascular response to air jet stress, and the GABAergic tonus, within the $\mathrm{DMH}$, in HFD-induced obese rats.

\section{METHODS}

\section{Ethical approval}

All procedures were approved by the ethics committee for animal research of the Federal University of Ouro Preto (CEUA-UFOP; \#2010/75), and were performed according to the regulations set forth by the National Institutes of Health Guidelines for the Care and Use of Laboratory Animals, and according to the journal policies and regulations on animal experimentation. All efforts were made to minimize the number of animals used in the present study, and to avoid any unnecessary distress to the animals.

\section{Animals}

Experiments were conducted on male Wistar rats $(n=29)$ at the Federal University of Ouro Preto (Brazil). The animals were housed in groups (three per cage), maintained in a dark-light cycle of $12 \mathrm{~h}$ and temperature maintained at $24^{\circ} \mathrm{C}$. Free access to food and water was allowed. Animals were acquired from the University Centre of Animal Sciences, weighting $100 \mathrm{~g}$ and then were divided in two experimental groups: a control group that was fed a commercial chow (Nuvilab, Brazil) $(11 \%$ $w / w$ of fat) and a HFD group that was fed a diet with $45 \% \mathrm{w} / \mathrm{w}$ of fat, which the composition was based on the diet sold by Research Diets, Inc., New Brunswick, NJ, USA (formula D12451) (Farley et al., 2003; Shklyaev et al., 2003). The animals were fed the respective diet for 9 weeks before the commencement of the procedures.

\section{Characterization of diet induced obesity}

Lee and adiposity indexes were used to evaluate the body composition status (i.e. obesity) in all animals. The Lee index (Stephens, 1980) was calculated by dividing the weight cubic root (in grams) by the body length (in centimeters), from the nose to the anus. The index is comparable to the body mass index used in humans. The adiposity index was calculated by dividing the visceral fat weight (the sum of epididymal, retroperitoneal and inguinal fat) by the rat weight and multiplying the result by 100 .

\section{Surgical procedures}

Surgical procedures started 9 weeks after initiation of diet treatment. Rats were anesthetized $\left(80 \mathrm{mg} \mathrm{kg}^{-1}\right.$ ketamine and $11.5 \mathrm{mg} \mathrm{kg}^{-1}$ xylazine, i.p., supplemented if needed) and guide cannulae (stainless steel) were implanted for microinjection of drugs into the $\mathrm{DMH}$ bilaterally, as described previously (Stotz-Potter et al., 1996a; StotzPotter et al., 1996b). Briefly, rats were placed in a stereotaxic apparatus with the incisor bar positioned at $3.3 \mathrm{~mm}$ below the level of the interaural line. The guide cannulae were positioned according to the coordinates of the Paxinos and Watson atlas (Paxinos and Watson, 2007) using bregma as a reference point; coordinates for the DMH: $3.2 \mathrm{~mm}$ posterior, $0.6 \mathrm{~mm}$ lateral, $7.5 \mathrm{~mm}$ ventral. Two screws and dental acrylic secured the guide cannulae. Animals were placed in individual cages for recovery. Rats were allowed at least 6 days for recovery before the beginning of the next surgery. After this period, a polyethylene catheter was inserted into the femoral artery (for cardiovascular measurements) of all animals under isoflurane anesthesia $(2.5 \%$ isoflurane in $3 \mathrm{~L} / \mathrm{min} \mathrm{O}_{2}$; Cristalia, Brazil). The catheter was tunneled subcutaneously and exteriorized on the back of the neck. After surgery, analgesics (ketoflex $4 \mathrm{mg} / \mathrm{kg}$, $0.1 \mathrm{ml} / 300 \mathrm{~g}$ s.c., Mundo Animal, Brazil) and antibiotics (penthabiotic, $0.2 \mathrm{ml} / 100 \mathrm{~g}$, s.c., Fort Dodge Animal Health, Brazil) were administered. The animals were maintained in individual cages in order to recover from the anesthesia. Experimental procedures began $48 \mathrm{~h}$ after the last surgery. 


\section{Cardiovascular measurements}

The arterial catheter was connected to a pressure transducer MLT0699 (ADI Instruments, Australia), which was connected to a signal amplifier ETH-400 (CB Sciences Inc., Dover, New Hampshire, USA). The analog signal from the amplifier was digitized by a 12-bit analog-to-digital converter (PowerLab/400, ADI Instruments, Australia), and the pulsatile arterial pressure recorded at $1000 \mathrm{~Hz}$ by the software Chart 7.0 for Windows (ADInstruments, Australia). MAP and HR were derived on-line from the pulsatile arterial pressure using pulse-to-pulse analysis.

\section{Experimental design}

Experiments were performed, as follow, in a room in which the temperature was maintained at $24-25^{\circ} \mathrm{C}$. On the day of the experiment, animals were brought to the experimental room, in their home cages, 2 hours prior to the beginning of the protocol. The experiment commenced only after stabilization of physiological parameters (HR and MAP) for at least $30 \mathrm{~min}$. Microinjections were performed with a microinjector (30 gauge, $1 \mathrm{~mm}$ longer than the guide cannulae) connected to a $5-\mu$ l Hamilton syringe with Teflon tubing (ID $0.12 \mathrm{~mm}$; OD $0.65 \mathrm{~mm}$; Bioanalytical Systems, West Lafayette, IN, USA). The syringe was used to deliver $100 \mathrm{nl}$ of injectate over $10 \mathrm{~s}$. The microinjection was considered successful if, immediately after removal of the microinjector, flow appeared immediately, indicating that the injector was not obstructed. Each rat was subjected to two different trials 2 days apart and in random order in which either saline vehicle $(100 \mathrm{nl})$ or a drug (i.e. muscimol or bicuculline) was injected into the $\mathrm{DMH}$.

The first series of experiments evaluated the influence of obesity on the cardiovascular changes induced by air jet stress, and on the GABAergic tonus within the $\mathrm{DMH}$. After stabilization, animals fed a control diet $(n=8)$ or a HFD $(n=8)$ received an injection of muscimol $(100 \mathrm{pmol} / 100 \mathrm{nl})$, a $\mathrm{GABA}_{\mathrm{A}}$ agonist, or saline into the $\mathrm{DMH}$, bilaterally. Seven minutes after the injections the animals were submitted to a 15 of air jet stress. This paradigm consists in placing the animal inside a container, and directing a hose, which blow an air stream (4l/min), to the animal head (de Menezes et al., 2008).

The second series of experiments evaluated the influence of obesity on the cardiovascular changes produced by the injection of a $\mathrm{GABA}_{\mathrm{A}}$ antagonist, Bicuculline Methiodide (BMI), into the $\mathrm{DMH}$. After stabilization, animals fed a control diet $(n=6)$ or a HFD $(n=7)$ received an injection of bicuculline (10 pmol/ $100 \mathrm{nl})$ or saline $(100 \mathrm{nl})$ into the $\mathrm{DMH}$.

At the completion of experiments, rats were deeply anesthetized with pentobarbital $\left(80 \mathrm{mg} \mathrm{kg}^{-1}\right.$, i.p.) and subjected to transcardiac perfusion with $60 \mathrm{ml}$ of saline followed by $120 \mathrm{ml}$ of $4 \%$ buffered paraformaldehyde in $0.1 \mathrm{M}$ phosphate-buffered saline. The brain was then removed, stored in $4 \%$ buffered paraformaldehyde overnight and then transferred to a $20 \%$ sucrose solution until saturation. Coronal sections $(40 \mu \mathrm{m})$ at the level of the $\mathrm{DMH}$ were cut on a cryostat, mounted on slides with PERMOUNT (Fisher Scientifics, Waltham, MA, USA), and coverslipped. Slides were examined using a Leica DM LB microscope (Diagnostics Instruments Inc., Starling Heights, MI, USA). Sites of injections were approximated using the atlas of Paxinos and Watson as a reference (Paxinos and Watson, 2007).

The epididymal, retroperitoneal and inguinal fat pads were removed so that the adiposity index could be calculated (see above).

\section{Statistical analysis}

Data for HR and MAP values were recorded continuously. For representation in figures changes from baseline were averaged over 3-min intervals, during and after the stress paradigm, and after the injection of BMI. The baseline values for MAP and HR were obtained by averaging the values of the 5-min period that preceded drug injections. Maximal changes (as means \pm standard error of the mean) were calculated using 3-min averages. The stress peak response was determined by averaging the 3-min period after the beginning of the procedure. For the calculation of mean changes at the end of the stress paradigm we used the average of the last $3 \mathrm{~min}$. The response to the injection of bicuculline into $\mathrm{DMH}$ was obtained by averaging a 3-min period of the maximal changes in MAP and HR. For the calculation of mean maximal changes in $\mathrm{HR}$ and MAP after bicuculline injections, we used the maximal change occurring within the first $6 \mathrm{~min}$ after microinjection. For calculation of the persistence of the response induced by bicuculline we used the average of the last $3 \mathrm{~min}$ (i.e. $20 \mathrm{~min}$ after the injections).

All data analyzed were obtained from animals that had the injection sites in the DMH confirmed by histology.

Prism 5.0 (GraphPad Software, La Jolla, CA, USA) was used to analyze all data. The data are expressed as mean \pm standard error of the mean (SEM). Student's paired $t$-test was used to analyze the differences within groups. Student's unpaired $t$-test or two-way (diet and drug as factors) repeated measures analysis of variance (ANOVA) with post hoc comparison with Bonferroni post-test were used to analyze differences between groups. The significance threshold level was set at 0.05 .

\section{RESULTS}

\section{HFD-induced obesity}

Obesity was successfully induced in animals fed a HFD, as characterized by the increased weight gain, higher body weight and elevated Lee and the adiposity indexes, at the end of the diet protocol, when compared to the animals fed the control diet $(p<0.05$, by Student's unpaired $t$-test) (Table 1).

Animals fed a HFD presented a significantly higher baseline MAP and HR in comparison with control animals (Table 2). 
Table 1. Effect of control and high-fat $(45 \% \mathrm{w} / \mathrm{w})$ diets for 9 weeks on rat's body composition

\begin{tabular}{cclc}
\hline & $\begin{array}{l}\text { Control diet } \\
(n=14)\end{array}$ & $\begin{array}{l}\text { High-fat diet } \\
(n=15)\end{array}$ & $P$ value \\
\hline $\begin{array}{c}\text { Initial body } \\
\text { weight }(g)\end{array}$ & $97.06 \pm 2.09$ & $102.00 \pm 2.66$ & 0.0887 \\
$\begin{array}{c}\text { Final body } \\
\text { weight }(g)\end{array}$ & $283.40 \pm 8.20$ & $338.60 \pm 7.94^{\#}$ & 0.0003 \\
$\begin{array}{c}\text { Body weight } \\
\text { gain (g) }\end{array}$ & $186,30 \pm 9.54$ & $236.60 \pm 7.09^{\#}$ & $<0.0001$ \\
$\begin{array}{c}\text { Lee index } \\
\text { Adiposity } \\
\text { index }\end{array}$ & $0.27 \pm 0.002$ & $0.30 \pm 0.002^{\#}$ & $<0.0001$ \\
\hline
\end{tabular}

Values are means $\pm \mathrm{SE} ; n$, number of rats.

* [Body weight $(\mathrm{g})]^{1 / 3} /$ nasoanal length $(\mathrm{cm})$.

** Body fat mass $(\mathrm{g}) /$ final body weight $(\mathrm{g}) \times 100$.

\# Significant difference between high-fat diet versus control diet group by Student's unpaired $t$-test.

Table 2. Effect of control and high-fat (45\%) diets on baseline HR and MAP

\begin{tabular}{llll}
\hline & $\begin{array}{l}\text { Control diet } \\
(n=14)\end{array}$ & $\begin{array}{l}\text { High-fat diet } \\
(n=15)\end{array}$ & $P$ value \\
\hline MAP $(\mathrm{mmHg})$ & $109.1 \pm 1.2$ & $114.7 \pm 1.6^{*}$ & 0.0076 \\
HR $(\mathrm{bpm})$ & $370.3 \pm 7.6$ & $392.8 \pm 5.1^{*}$ & 0.0153 \\
\hline
\end{tabular}

Values are means \pm SE; $n$ (number of rats), MAP (mean arterial pressure) and HR (heart rate).

* Significant difference between high-fat diet versus control diet group by Student's unpaired $t$-test.

\section{Influence of obesity on the increases of MAP and HR produced by air jet stress}

The air jet stress paradigm induced increases in MAP and $\mathrm{HR}$ in both groups. However, the obese rats had a higher increase in MAP $(18 \pm 2 \mathrm{mmHg}$ vs. $13 \pm 1 \mathrm{mmHg}$ in the controls, $p<0.05)$ and HR $(94 \pm 10 \mathrm{bpm}$ vs. $53 \pm 9 \mathrm{bpm}$, in the controls, $p<0.01$ ) (Fig. 1A-D).

\section{Effects of muscimol on the increases of MAP and HR produced by air jet stress in obese rats}

The injection of muscimol (100 pmol/100 nl) into the DMH of rats fed a control diet significantly reduced the increases in MAP evoked by air jet stress when compared to the vehicle injection (Fig. 1A, C). In rats fed a HFD the injection of this same dose of muscimol, into the $\mathrm{DMH}$, also reduced the increase in MAP produced by air jet stress when compared to the vehicle treatment (Fig. 1A, C). Nevertheless, the injection of muscimol was less effective in reducing the increase in MAP evoked by air jet stress in the obese animals $(36 \pm 8 \%$ vs. $70 \pm 11 \%$ in the control group, $p=0.031$, by unpaired Student's $t$-test, Fig. 1C). Administration of muscimol reduced the maximal increases in HR evoked by air jet stress for both control and obese rats when compared to the saline treatment (Fig. 1B, D). On the other hand, although the injection of muscimol reduced the $\mathrm{HR}$ at the end of the stress procedure in the control group ( $6 \pm 7$ vs. $52 \pm 15 \mathrm{bpm}$ after saline; $p=0.044)$, this effect was not observed in the obese animals $(45 \pm 15$ vs. $63 \pm 11$ bpm; $p=0.44$, after saline; Fig. 1F). Post-mortem histology confirmed that injection sites were located in the $\mathrm{DMH}$, bilaterally (Figs. 2 and 5A, B).

\section{Effects of the injection of bicuculline on MAP and HR of obese rats}

The injection of bicuculline $(100 \mathrm{pmol} / 100 \mathrm{nl})$ into the $\mathrm{DMH}$ induced an increase in MAP and HR of control and obese animals (Fig. 3A-D). However, in rats fed a HFD the increase in HR was of a short duration, since that at the 20-min mark the HR levels were significantly lower in this group when compared to the control group $(13 \pm 4$ vs. $75 \pm 25 \mathrm{bpm}$; by two-way ANOVA, $p<0.05$ ) (Fig. 3F). Post-mortem histology confirmed that injection sites were located in the DMH bilaterally (Figs, 4 and 5C, D).

\section{DISCUSSION}

The present study demonstrates that obesity, induced by a HFD, potentiates the cardiovascular response produced by air jet stress in rats. This increased response is probably due to a reduced GABA-mediated inhibition within the $\mathrm{DMH}$, since activation of $\mathrm{GABA}_{\mathrm{A}}$ receptors was less efficient in reducing the increase in MAP evoked by air stress in obese rats. Moreover, the injection of muscimol into the $\mathrm{DMH}$ of obese animals reduced the tachycardia only in the beginning of the air stress protocol. In keeping with these findings, the blockade of $\mathrm{GABA}_{\mathrm{A}}$ receptors, within the $\mathrm{DMH}$, produced an increase in HR and MAP, as expected, nonetheless the duration of the $H R$ response was shorter in the obese animals. Although previous studies have demonstrated that obesity can produced a greater cardiovascular response to emotional stress (Sedova et al., 2004; D'Angelo et al., 2006), our study is the first to demonstrate that the increased cardiovascular reactivity to stress in obese animals derives from an impairment of the GABAergic system within the $\mathrm{DMH}$.

Our results have confirmed that the increase in the dietary fat content for several weeks induce obesity in rats (Nagae et al., 2009). The obesity was characterized by the increased weight, increased Lee index, and more importantly, by an increased amount of visceral fat in animas fed a HFD (Nagae et al., 2009; Marco et al., 2013; Martinez-Martinez et al., 2013; McCully et al., 2013; Song et al., 2013). Previous studies have linked visceral obesity with an increased cardiovascular risk (Despres et al., 2001), as well as with other states such as insulin resistance and diabetes (Sethi and Vidal-Puig, 2005; Foster et al., 2010, 2011).

The obese rats presented increased baseline levels of $\mathrm{HR}$ and blood pressure, in accordance to previous data (Smith et al., 2006; Nagae et al., 2009). It is well known that the sympathetic activity is augmented during obesity and that this increase could lead to high blood pressure (see Esler et al., 2006). The enhancement of sympathetic activity, which probably leads to the baseline HR and MAP changes, could be due to a 
A $^{25}$

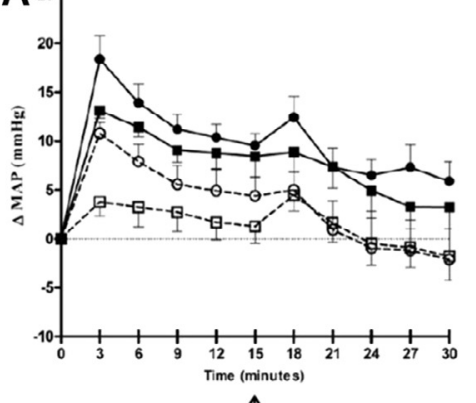

$\uparrow$

C
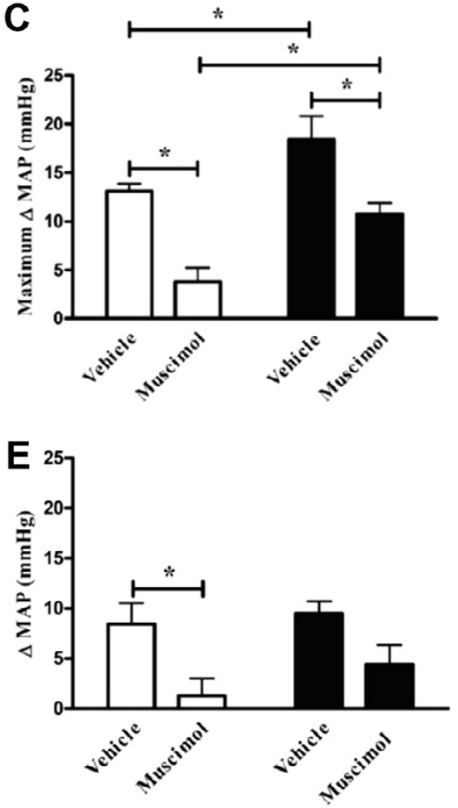

B

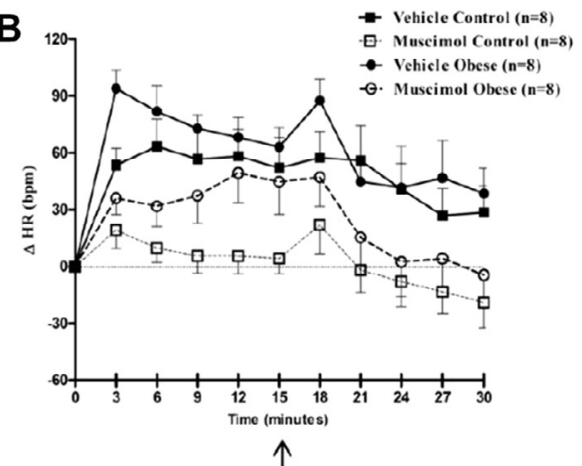

D
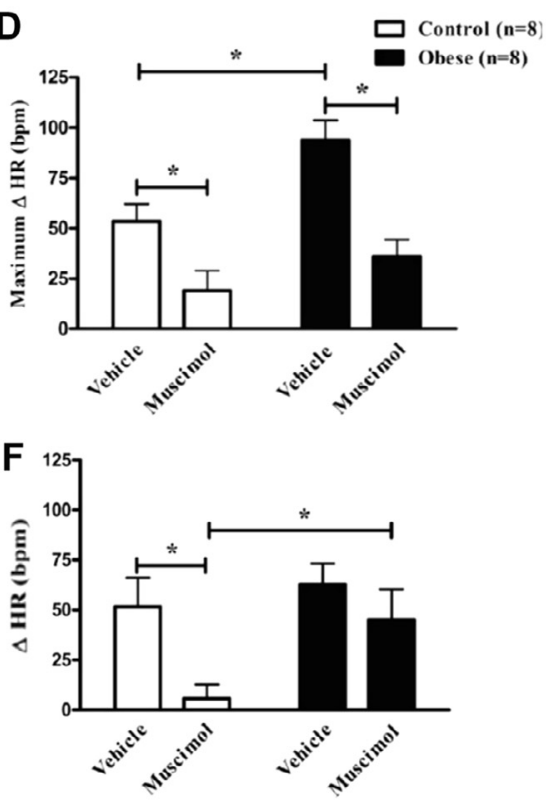

G

Control (standart diet)

H

Obese (high fat diet)
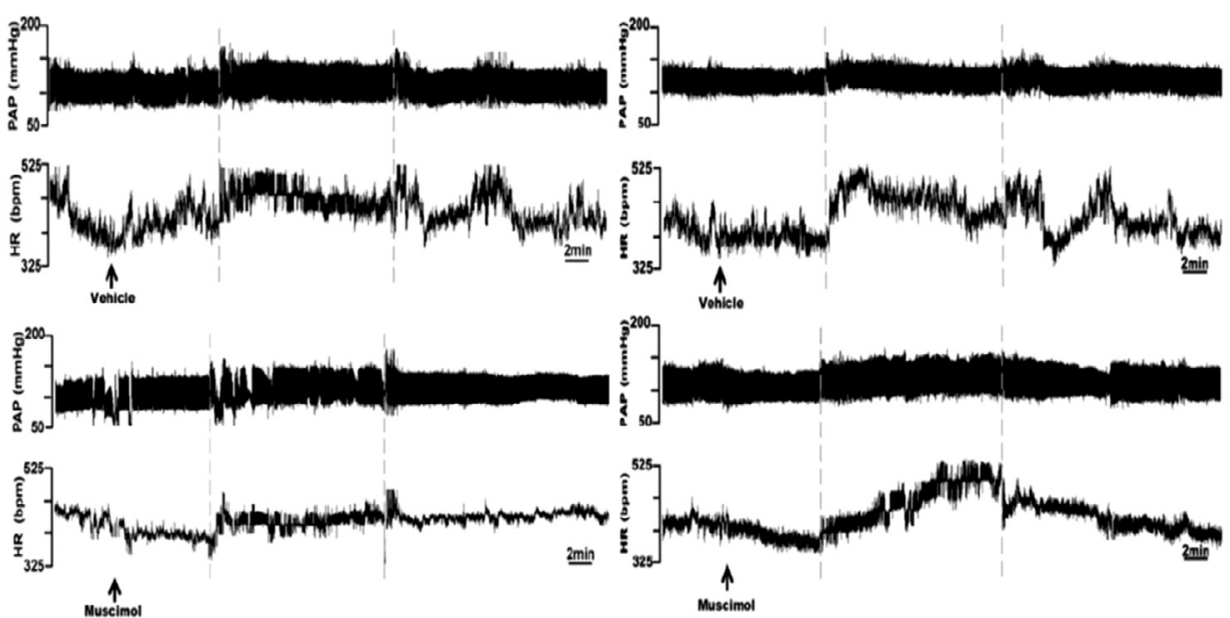

Fig. 1. Obese rats have an increased cardiovascular reactivity to emotional stress. $A, B$ - Mean changes from baseline for MAP (A) and HR (B) over time $(\mathrm{min})$ induced by air jet stress after microinjection of vehicle $(100 \mathrm{nl})$ or muscimol $(100 \mathrm{pmol} / 100 \mathrm{nl})$ into the DMH of rats fed a control or a high fat. Arrows indicate the end of the air jet stress paradigm. C, D - Maximum changes (mean \pm SEM) in MAP (C) and HR (D) induced by air jet stress, after microinjection of vehicle or muscimol into the DMH of rats fed a control or a high-fat diet. E, F - Changes (mean \pm SEM) in MAP (E) and HR $(F)$ at the end of air stress after microinjection of vehicle or muscimol into the DMH of rats fed a control $(n=9)$ or a high-fat diet $(n=8)$. ${ }^{*} p<0.05$ Capped lines indicate statistical differences. Comparison within groups by paired Student's $t$-test; Comparison between groups by a twofactor repeated measures ANOVA followed by the Bonferroni post hoc test (treatment and diet as factors). G, $\mathrm{H}$ - original recordings showing the effects of vehicle (top panel) or muscimol [bottom panel] injections into the $\mathrm{DMH}$, on cardiovascular changes evoked by air jet stress (dotted lines) in a rat fed a standard diet $(\mathrm{G})$ or in a rat fed a high-fat diet $(\mathrm{H})$. Recordings of pulsatile arterial pressure (PAP; top trace) and HR (bottom trace) and) are shown. ${ }^{*} p<0.05$ Capped lines indicate statistical differences. Comparison within groups by paired Student's $t$-test; comparison between groups by a two-factor repeated measures ANOVA followed by the Bonferroni post hoc test (treatment and diet as factors). 

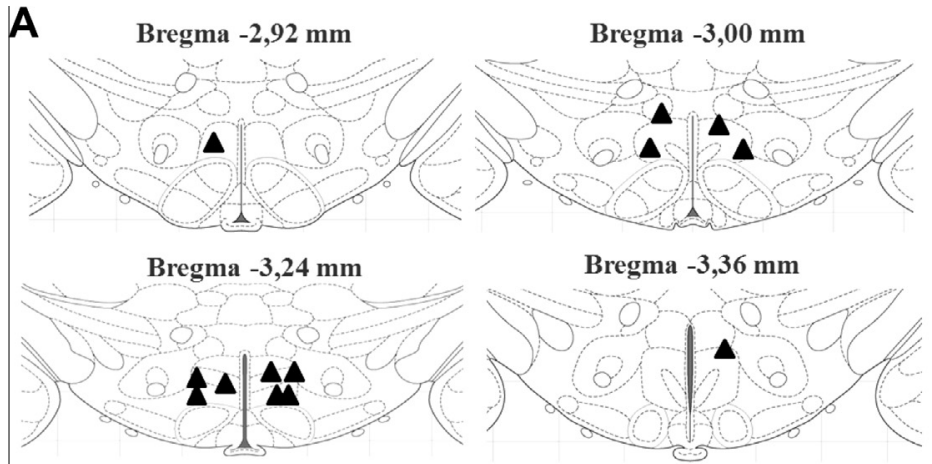

Bregma $-3,36 \mathrm{~mm}$

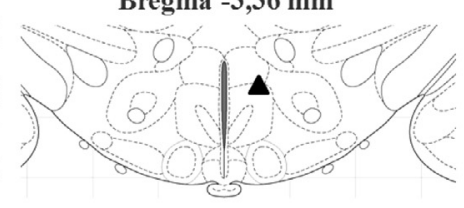

B
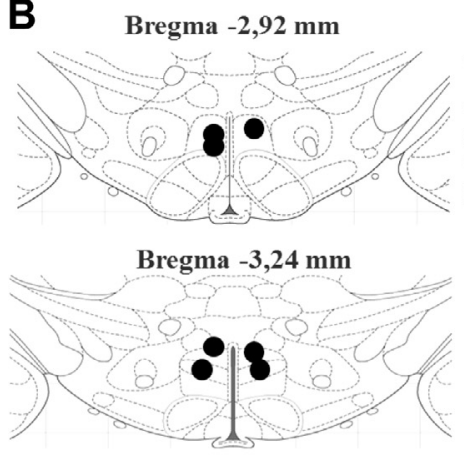
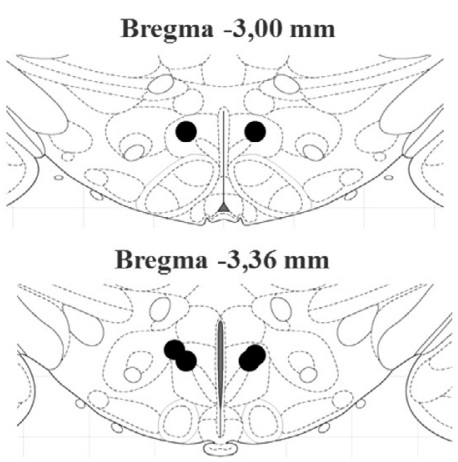

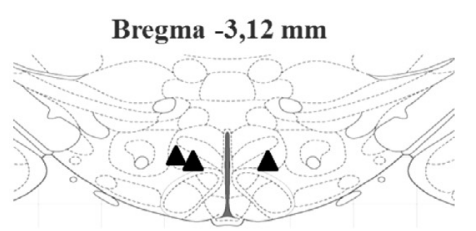

Bregma $-3,48 \mathrm{~mm}$
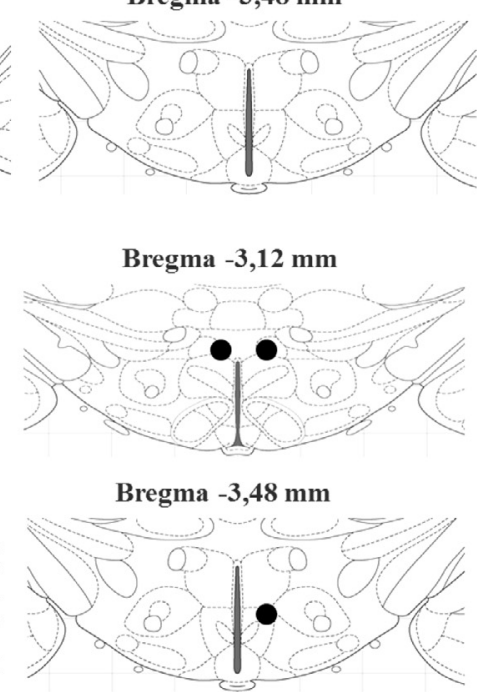

Fig. 2. Sites of injection in $\mathrm{DMH}$, bilaterally, in the air stress experiments. Schematic coronal sections of the rat brain adapted from the atlas of Paxinos and Watson (2007)) illustrating approximate sites of injections of saline or muscimol into DMH, bilaterally, of control (A - black triangles, $n=9)$ and obese (B - black circles, $n=8)$ rats.

higher activation of the DMH during resting conditions. Studies have demonstrated that the stimulation of DMH neurons leads to increases in the sympathetic discharge to different organs (Fontes et al., 2001; Cao and Morrison, 2006). Interestingly, obese mice have an augmented neuronal activation within the $\mathrm{DMH}$ in resting conditions, as demonstrated by the increased cfos expression (Xin et al., 2000).

When the control animals were subjected to air jet stress their HR and MAP increased as expected (Soltis and DiMicco, 1992; Stotz-Potter et al., 1996b; de Menezes et al., 2008). However, the obese animals were more responsive to the stress paradigm, presenting a greater increase in HR and MAP when compared to lean animals. This data is in accordance with a previous study using the Obese Zucker rats, which showed that these animals have an exaggerated response to stress. Conversely, Armitage and colleagues, have shown that in rabbits the cardiovascular response to airjet stress is reduced after three (3) weeks feeding on a HFD (Armitage et al., 2012). This difference could be accounted by the fact that our rats were fed a HFD for nine (9) weeks instead of only 3 weeks. Additionally, the HFD used in their study contained only $13 \%$ of fat compared to the $45 \%$ fat content in the diet used in the present study.

The amplified cardiovascular response to stress in obese animals could be attributable to functional changes in the DMH neurons. It is important to notice that the $\mathrm{DMH}$ is an essential integrative site to the stress response (DiMicco et al., 2002). Therefore, if the DMH neurons are, in fact, more excitable in the obese animals, this could be the cause of the increased cardiovascular reactivity to emotional stress observed in these animals.

In order to further understand the role of the $\mathrm{DMH}$ in the modified cardiovascular response to emotional stress in obese animals, we have investigated the role of the GABA neurotransmission in the $\mathrm{DMH}$ in these changes. The injection of a $G_{A B A}$ agonist muscimol into the DMH reduced the increases in HR and MAP evoked by air jet stress in the rats fed a control diet, as described previously (Stotz-Potter et al., 1996a; StotzPotter et al., 1996b). On the other hand, the injection of the same dose of muscimol in the DMH of obese animals did not reduce the increase in MAP produced by emotional stress in obese animals, though it reduced the tachycardia in the beginning of the stress procedure. This reduction was not present at the end of the procedure, where the level of HR was much greater in the obese than in the control animals. A reduced sensitivity to an exogenous GABA agonist suggests an impairment of the GABA-mediated inhibition within the $\mathrm{DMH}$, which usually restrains sympathetic drive during stress in control animals (DiMicco et al., 2002), and might be the cause of the potentiated response to stress in the obese rats.

The blockade of the $\mathrm{GABA}_{\mathrm{A}}$ receptors, by bicuculline, within the $\mathrm{DMH}$ produced a tachycardic and hypertensive response in both lean and obese animals. However, the HR response in the obese animals was shorter than in lean animals, which is consistent with an impaired GABA-mediated inhibition. One possible explanation for 
A
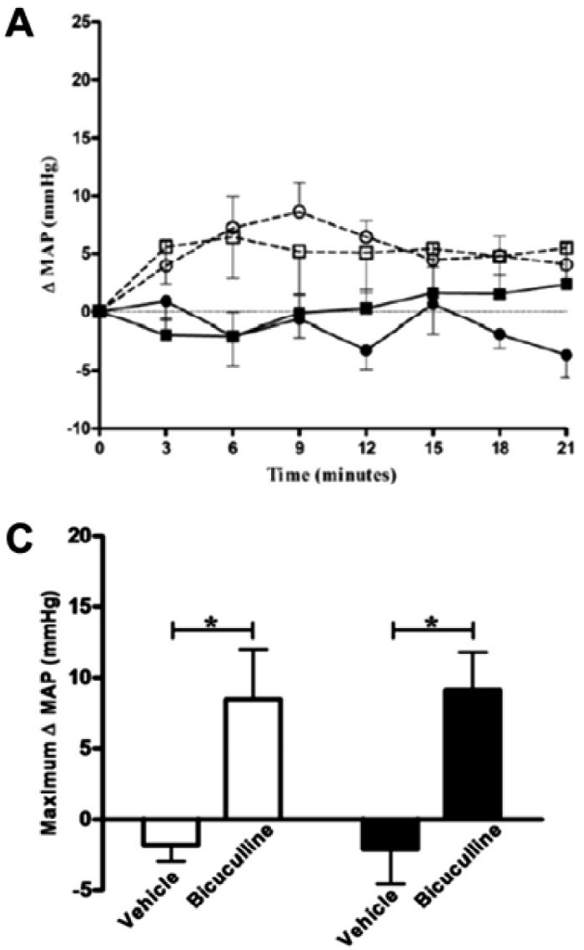

E

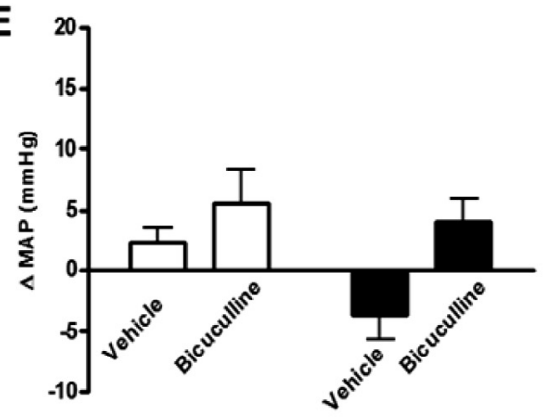

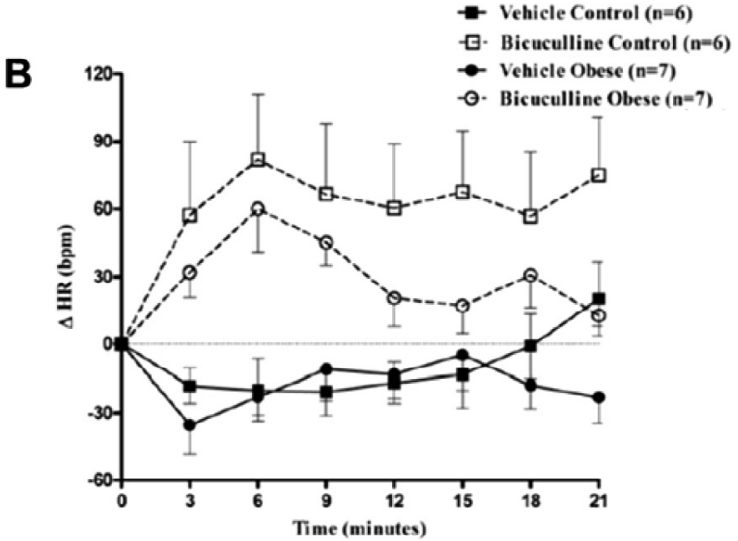

D

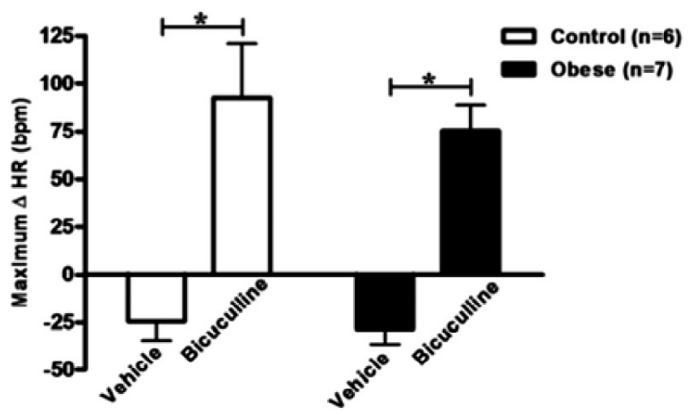

$\mathbf{F}$

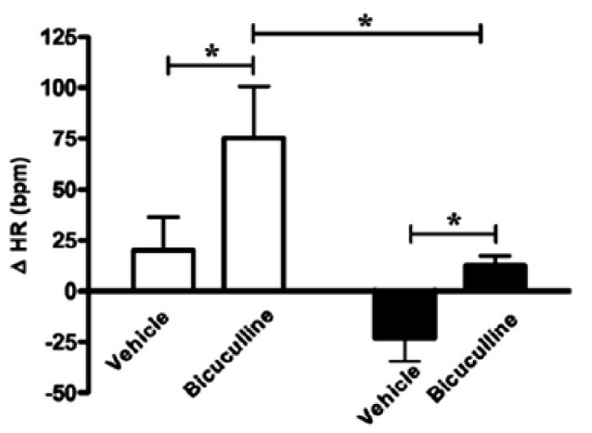

G Control (standart diet)

H

Obese (high fat diet)
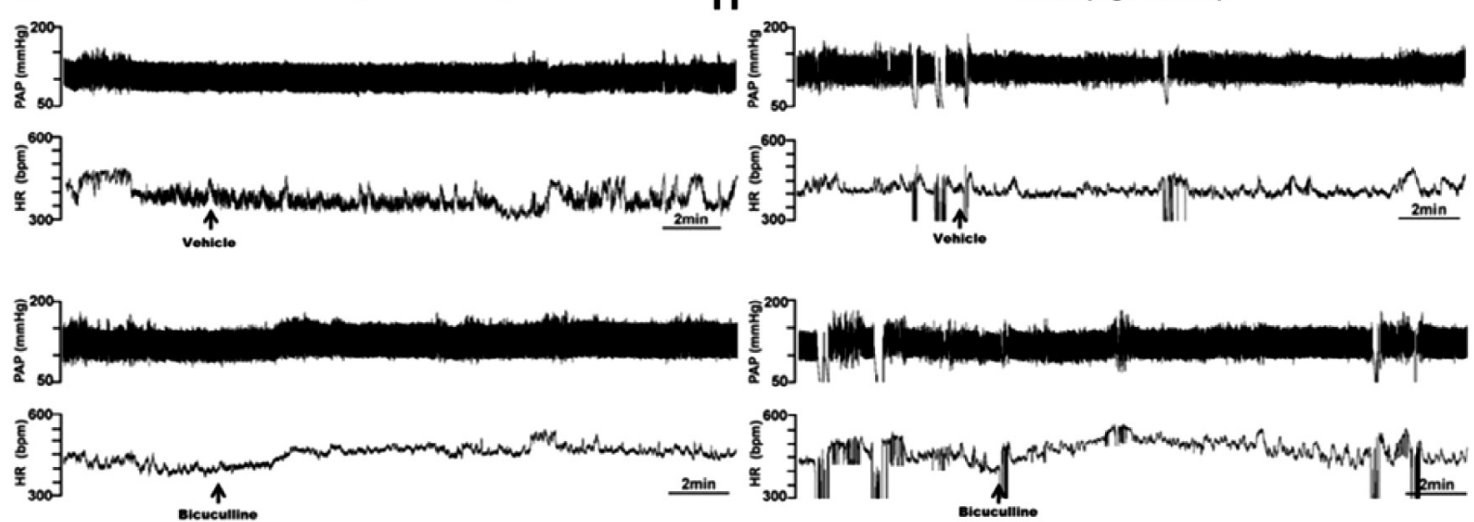

Fig. 3. Effect of injection of bicuculline into the DMH of obese and control animals on HR and MAP. A, B - Mean changes from baseline for MAP (A) and HR (B) over time ( $\mathrm{min})$ induced by microinjection of vehicle $(100 \mathrm{nl})$ or bicuculline $(10 \mathrm{pmol} / 100 \mathrm{nl})$ into the DMH of rats fed a control or a high-fat diet. C, D-Maximum changes (mean \pm SEM) in MAP (C) and HR (D) induced by the microinjection of vehicle or bicuculline into the DMH of rats fed a control or a high-fat diet. E, F - Final values (mean \pm SEM) of MAP (E) and HR (F), i.e. 20 min after the injection of vehicle or bicuculline into the DMH of rats fed a control $(n=6)$ or a high-fat diet $(n=7) .{ }^{*} p<0.05$ Capped lines indicate statistical differences. Comparison within groups by paired Student's $t$-test; Comparison between groups by a two-factor repeated measures ANOVA followed by the Bonferroni post hoc test (treatment and diet as repeated factors). $\mathrm{G}, \mathrm{H}$ - original recordings showing the cardiovascular effects of the injection of vehicle (top panel) or bicuculline [bottom panel] into the $\mathrm{DMH}$, in a rat fed a standard diet $(\mathrm{G})$ or in a rat fed a high-fat diet $(\mathrm{H})$. Recordings of pulsatile arterial pressure (PAP; top trace) and HR (bottom trace) are shown. ${ }^{*} p<0.05$ Capped lines indicate statistical differences. Comparison within groups by paired Student's $t$-test; comparison between groups by a two-factor repeated measures ANOVA followed by the Bonferroni post hoc test (treatment and diet as factors). 
A

Aregma $-2,92 \mathrm{~mm}$

Bregma $-3,00 \mathrm{~mm}$
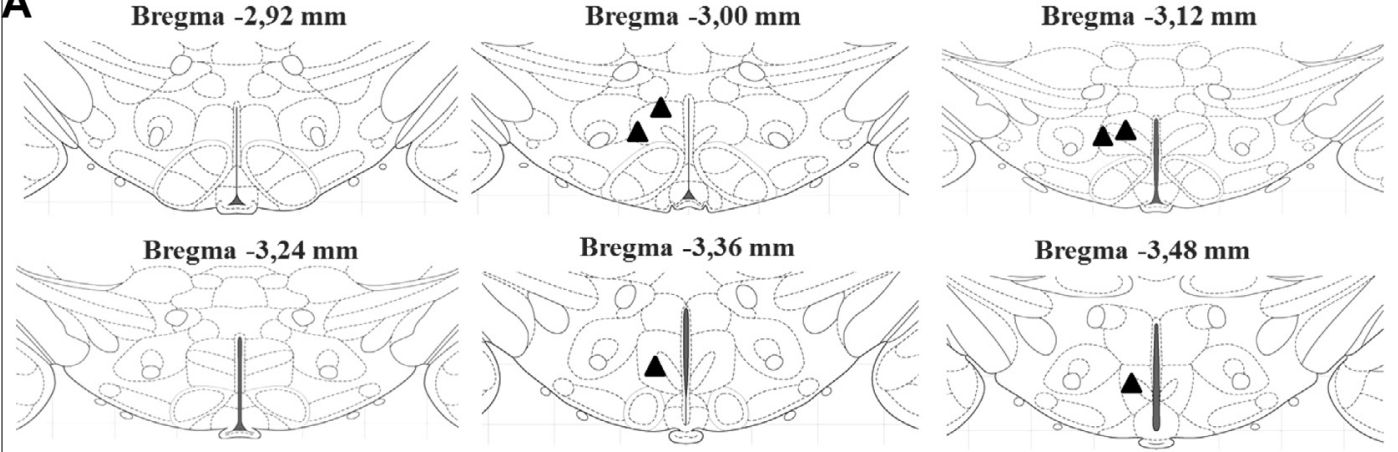

B
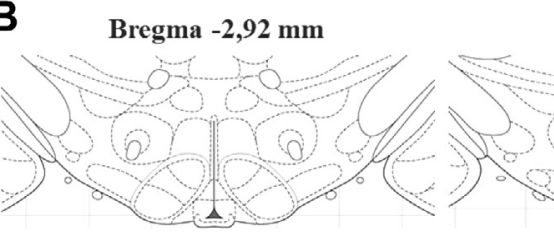

Bregma $-3,00 \mathrm{~mm}$
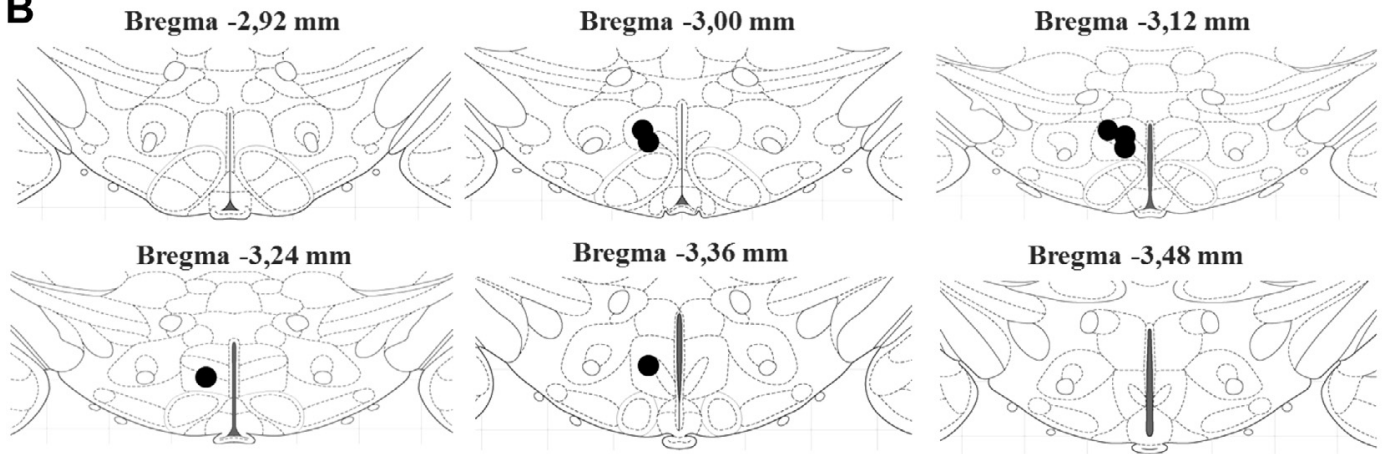

Fig. 4. Sites of injection of bicuculline in DMH. Schematic coronal sections of the rat brain adapted from the atlas of Paxinos and Watson (2007) illustrating approximate sites of injections of saline or bicuculline into $\mathrm{DMH}$, unilaterally, of control $(\mathrm{A}-$ black triangles, $n=6)$ and obese $(\mathrm{B}-$ black circles, $n=7$ ) rats.
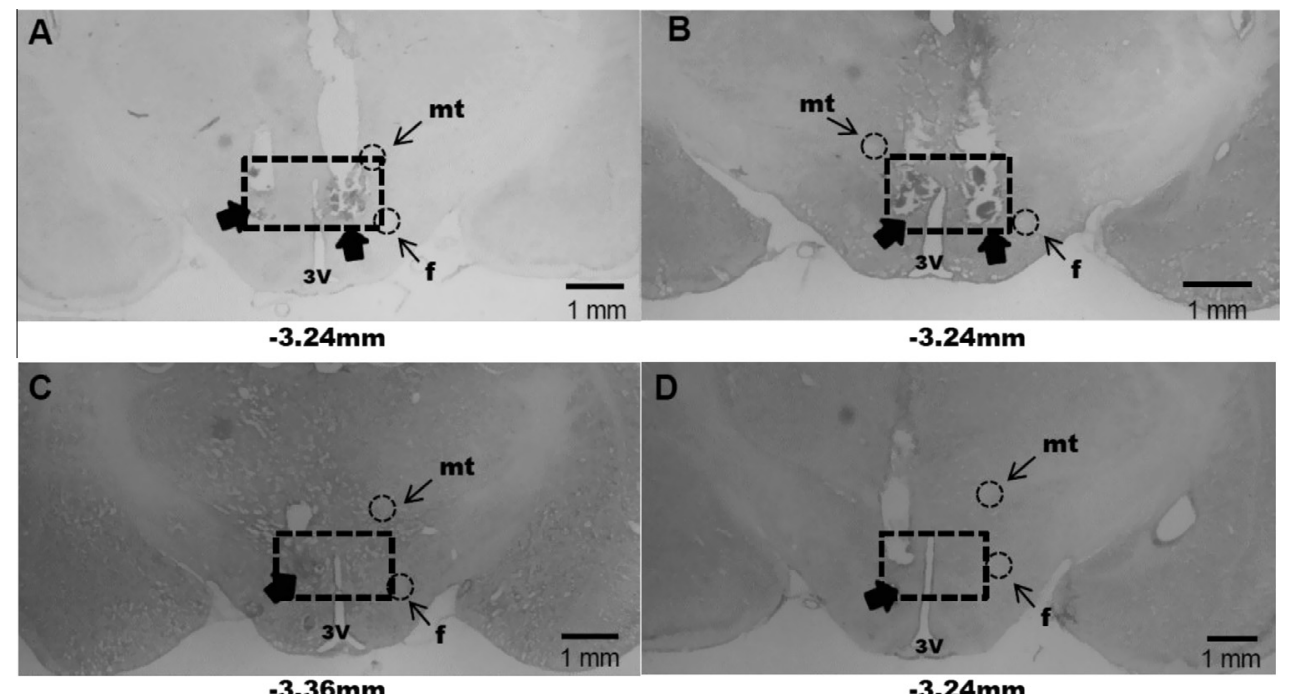

Fig. 5. Examples of typical sites of injections into the DMH of control and obese rats. A, B - Typical bilateral sites of injection (filled arrows) into the $\mathrm{DMH}$ of control (A) and obese (B) rats C, D - Typical unilateral sites of injection into the DMH of control (C) and obese (D) rats. Dashed rectangle represents the $\mathrm{DMH}$ area bilaterally. $3 \mathrm{~V}$, third ventricle; $f$, fornix; $\mathrm{mt}$, mammillothalamic tract.

the reduced response to $\mathrm{GABA}_{\mathrm{A}}$ blockade would be a deficit in the release of GABA-containing vesicles. Data suggest that neuropeptide $\mathrm{Y}(\mathrm{NPY})$ can inhibit GABA release in the hypothalamus (Walker et al., 1988; Premkumar and Ahern, 2000). Particularly, NPY levels are elevated in obese animals (Guan et al., 1998; Tritos et al., 1998; $\mathrm{Bi}$ et al., 2001). The increased NPY concentration would reduce the amount of GABA available in the synaptic shaft limiting the interaction between neurotransmitter and its receptor, partly explaining the blunted cardiovascular responses induced by $\mathrm{GABA}_{\mathrm{A}}$ blockade in obese rats.

The GABA-inhibition deficit could also be produced by obesity-induced inflammation. It is known that in peripheral tissues, obesity is associated with a chronic low-grade inflammation (for review see Gregor and 
Hotamisligil, 2011), however, the potential contribution of obesity-associated neuroinflammation to CNS pathologies is only beginning to be recognized (Drake et al., 2011; Buckman et al., 2013). For instance, heart failure increases proinflammatory cytokines in the hypothalamic paraventricular nucleus (PVN), which cause a reduction in GABA-mediated inhibition within the PVN, contributing to the sympathoexcitation observed in this condition (Kang et al., 2011). Moreover, obesity-induced neuroinflammation leads to the induction of reactive astrogliosis in various hypothalamic nuclei, such as the $\mathrm{DMH}$ and the median pre-optic area (Buckman et al., 2013). Notably, astrogliosis reduces inhibitory, but not excitatory, synaptic currents, due to a failure of the astrocytic glutamate-glutamine cycle (Ortinski et al., 2010); thus, astrogliosis may have a significant impact on the deficit in neuronal inhibition, within the $\mathrm{DMH}$, observed in the obese animals. Moreover, the neuroinflammation induced by obesity could lead to localized edema. The increased amount of water could facilitate the diffusion of the BMI, and therefore reducing the time course of $\mathrm{BMI}$ action without truly changing the $\mathrm{GABA}_{A}$ system.

The reduction on the GABA-mediated inhibition within the $\mathrm{DMH}$, caused by a reduction in the release of GABA or by a defective receptor, could be a main factor in the increased cardiovascular reactivity to emotional stress in obese rats. This impairment of the GABA system would allow the response to occur without the restraint that this system usually provides (DiMicco et al., 2002), thus increasing neuronal activation. The increased baseline levels of blood pressure and HR could also be explained by this deficit in GABA neurotransmission. Without the influence of GABA during resting conditions, the $\mathrm{DMH}$ neurons would be more influenced by the tonic excitatory drive that is normally present (DiMicco et al., 2002; de Menezes et al., 2009), therefore increasing basal blood pressure and HR.

\section{CONCLUSION}

The present study shows that the cardiovascular reactivity to emotional stress is increased in HFDinduced obese rats because of an inefficient $G_{A B A}$ mediated inhibition within the $\mathrm{DMH}$. The excessive cardiovascular response to emotional stress, combined with the high levels of blood pressure and HR in resting conditions, observed in obese animals, could ultimately overload the cardiovascular system. This overwork could contribute to the development of the cardiovascular diseases usually associated with stress and obesity, such as hypertension and arrhythmias.

Acknowledgments-This work was supported by FAPEMIG, $P R O N E X-\# C B B-A P Q-04758-10$, the Coordenação de Aperfeiçoamento de Pessoal de Nível Superior (CAPES), and the Conselho Nacional de Desenvolvimento Científico e Tecnológico (CNPq).

\section{REFERENCES}

Alvarez GE, Beske SD, Ballard TP, Davy KP (2002) Sympathetic neural activation in visceral obesity. Circulation 106:2533-2536.

Amiragova MG (1985) Neurophysiological analysis of the development of endocrine and hypertensive reactions in prolonged emotional stress. Brain Res 344:303-315.

Armitage JA, Burke SL, Prior LJ, Barzel B, Eikelis N, Lim K, Head GA (2012) Rapid onset of renal sympathetic nerve activation in rabbits fed a high-fat diet. Hypertension 60:163-171.

Bi S, Ladenheim EE, Schwartz GJ, Moran TH (2001) A role for NPY overexpression in the dorsomedial hypothalamus in hyperphagia and obesity of OLETF rats. Am J Physiol Regul Integr Comp Physiol 281:R254-R260.

Buckman LB, Thompson MM, Moreno HN, Ellacott KL (2013) Regional astrogliosis in the mouse hypothalamus in response to obesity. J Comp Neurol 521:1322-1333.

Cao WH, Morrison SF (2006) Glutamate receptors in the raphe pallidus mediate brown adipose tissue thermogenesis evoked by activation of dorsomedial hypothalamic neurons. Neuropharmacology 51:426-437.

Clark JD, Rager DR, Calpin JP (1997) Animal well-being. II. Stress and distress. Lab Anim Sci 47:571-579.

da Silva LG, de Menezes RC, dos Santos RA, Campagnole-Santos MJ, Fontes MA (2003) Role of periaqueductal gray on the cardiovascular response evoked by disinhibition of the dorsomedial hypothalamus. Brain Res 984:206-214.

da Silva Jr LG, Menezes RC, Villela DC, Fontes MA (2006) Excitatory amino acid receptors in the periaqueductal gray mediate the cardiovascular response evoked by activation of dorsomedial hypothalamic neurons. Neuroscience 139:1129-1139.

D'Angelo G, Mintz JD, Tidwell JE, Schreihofer AM, Pollock DM, Stepp DW (2006) Exaggerated cardiovascular stress responses and impaired beta-adrenergic-mediated pressor recovery in obese Zucker rats. Hypertension 48:1109-1115.

de Menezes RC, Zaretsky DV, Fontes MA, DiMicco JA (2006) Microinjection of muscimol into caudal periaqueductal gray lowers body temperature and attenuates increases in temperature and activity evoked from the dorsomedial hypothalamus. Brain Res 1092:129-137.

de Menezes RC, Zaretsky DV, Sarkar S, Fontes MA, Dimicco JA (2008) Microinjection of muscimol into the periaqueductal gray suppresses cardiovascular and neuroendocrine response to air jet stress in conscious rats. Am J Physiol Regul Integr Comp Physiol 295:R881-R890.

de Menezes RC, Zaretsky DV, Fontes MA, DiMicco JA (2009) Cardiovascular and thermal responses evoked from the periaqueductal grey require neuronal activity in the hypothalamus. J Physiol 587:1201-1215.

Despres JP, Lemieux I, Prud'homme D (2001) Treatment of obesity: need to focus on high risk abdominally obese patients. BMJ 322:716-720.

DiMicco JA, Samuels BC, Zaretskaia MV, Zaretsky DV (2002) The dorsomedial hypothalamus and the response to stress: part renaissance, part revolution. Pharmacol Biochem Behav 71:469-480.

Drake C, Boutin H, Jones MS, Denes A, McColl BW, Selvarajah JR, Hulme S, Georgiou RF, Hinz R, Gerhard A, Vail A, Prenant C, Julyan P, Maroy R, Brown G, Smigova A, Herholz K, Kassiou M, Crossman D, Francis S, Proctor SD, Russell JC, Hopkins SJ, Tyrrell PJ, Rothwell NJ, Allan SM (2011) Brain inflammation is induced by co-morbidities and risk factors for stroke. Brain Behav Immun 25:1113-1122.

Eckel RH (1997) Obesity and heart disease: a statement for healthcare professionals from the Nutrition Committee, American Heart Association. Circulation 96:3248-3250.

Esler M, Straznicky N, Eikelis N, Masuo K, Lambert G, Lambert E (2006) Mechanisms of sympathetic activation in obesity-related hypertension. Hypertension 48:787-796. 
Farley C, Cook JA, Spar BD, Austin TM, Kowalski TJ (2003) Meal pattern analysis of diet-induced obesity in susceptible and resistant rats. Obes Res 11:845-851.

Fontes MA, Tagawa T, Polson JW, Cavanagh SJ, Dampney RA (2001) Descending pathways mediating cardiovascular response from dorsomedial hypothalamic nucleus. Am J Physiol Heart Circ Physiol 280:H2891-H2901.

Fontes MA, Xavier CH, de Menezes RC, Dimicco JA (2011) The dorsomedial hypothalamus and the central pathways involved in the cardiovascular response to emotional stress. Neuroscience 184:64-74.

Foster MT, Shi H, Seeley RJ, Woods SC (2010) Transplantation or removal of intra-abdominal adipose tissue prevents age-induced glucose insensitivity. Physiol Behav 101:282-288.

Foster MT, Shi H, Seeley RJ, Woods SC (2011) Removal of intraabdominal visceral adipose tissue improves glucose tolerance in rats: role of hepatic triglyceride storage. Physiol Behav 104:845-854.

Gregor MF, Hotamisligil GS (2011) Inflammatory mechanisms in obesity. Annu Rev Immunol 29:415-445.

Guan XM, Yu H, Trumbauer M, Frazier E, Van der Ploeg LH, Chen H (1998) Induction of neuropeptide $Y$ expression in dorsomedial hypothalamus of diet-induced obese mice. Neuroreport 9:3415-3419.

Huggett RJ, Burns J, Mackintosh AF, Mary DA (2004) Sympathetic neural activation in nondiabetic metabolic syndrome and its further augmentation by hypertension. Hypertension 44:847-852.

Kang YM, Gao F, Li HH, Cardinale JP, Elks C, Zang WJ, Yu XJ, Xu YY, Qi J, Yang Q, Francis J (2011) NF-kappaB in the paraventricular nucleus modulates neurotransmitters and contributes to sympathoexcitation in heart failure. Basic Res Cardiol 106:1087-1097.

Kuniyoshi FH, Trombetta IC, Batalha LT, Rondon MU, Laterza MC, Gowdak MM, Barretto AC, Halpern A, Villares SM, Lima EG, Negrao CE (2003) Abnormal neurovascular control during sympathoexcitation in obesity. Obes Res 11:1411-1419.

Leor J, Poole WK, Kloner RA (1996) Sudden cardiac death triggered by an earthquake. N Engl J Med 334:413-419.

Marco A, Kisliouk T, Weller A, Meiri N (2013) High fat diet induces hypermethylation of the hypothalamic Pomc promoter and obesity in post-weaning rats. Psychoneuroendocrinology.

Martinez-Martinez E, Miana M, Jurado-Lopez R, Rousseau E, Rossignol P, Zannad F, Cachofeiro V, Lopez-Andres N (2013) A role for soluble ST2 in vascular remodeling associated with obesity in rats. PLoS One 8:e79176.

Masuo K, Mikami H, Itoh M, Ogihara T, Tuck ML (2000) Sympathetic activity and body mass index contribute to blood pressure levels. Hypertens Res 23:303-310.

McCully BH, Hasan W, Streiff CT, Houle JC, Woodward WR, Giraud GD, Brooks VL, Habecker BA (2013) Sympathetic cardiac hyperinnervation and atrial autonomic imbalance in diet-induced obesity promote cardiac arrhythmias. Am J Physiol Heart Circ Physiol 305:H1530-H1537.

Modan M, Halkin H, Almog S, Lusky A, Eshkol A, Shefi M, Shitrit A, Fuchs Z (1985) Hyperinsulinemia. A link between hypertension obesity and glucose intolerance. J Clin Invest 75:809-817.

Morgan DA, Anderson EA, Mark AL (1995) Renal sympathetic nerve activity is increased in obese Zucker rats. Hypertension 25:834-838.

Nagae A, Fujita M, Kawarazaki H, Matsui H, Ando K, Fujita T (2009) Sympathoexcitation by oxidative stress in the brain mediates arterial pressure elevation in obesity-induced hypertension. Circulation 119:978-986.

Ootsuka Y, Blessing WW, Nalivaiko E (2008) Selective blockade of 5HT2A receptors attenuates the increased temperature response in brown adipose tissue to restraint stress in rats. Stress 11:125-133.
Ortinski PI, Dong J, Mungenast A, Yue C, Takano H, Watson DJ, Haydon PG, Coulter DA (2010) Selective induction of astrocytic gliosis generates deficits in neuronal inhibition. Nat Neurosci 13:584-591.

Paxinos G, Watson C (2007) The rat brain in stereotaxic coordinates. Amsterdam: Academic Press.

Premkumar LS, Ahern GP (2000) Induction of vanilloid receptor channel activity by protein kinase C. Nature 408:985-990.

Rumantir MS, Vaz M, Jennings GL, Collier G, Kaye DM, Seals DR, Wiesner GH, Brunner-La Rocca HP, Esler MD (1999) Neural mechanisms in human obesity-related hypertension. J Hypertens 17:1125-1133.

Sedova L, Berube J, Gaudet D, Dumont M, Tremblay J, Hamet P, Pausova Z (2004) Diet-induced obesity delays cardiovascular recovery from stress in spontaneously hypertensive rats. Obes Res 12:1951-1958.

Sethi JK, Vidal-Puig A (2005) Visfatin: the missing link between intraabdominal obesity and diabetes? Trends Mol Med 11:344-347.

Shekhar A, DiMicco JA (1987) Defense reaction elicited by injection of GABA antagonists and synthesis inhibitors into the posterior hypothalamus in rats. Neuropharmacology 26:407-417.

Shklyaev S, Aslanidi G, Tennant M, Prima V, Kohlbrenner E, Kroutov V, Campbell-Thompson M, Crawford J, Shek EW, Scarpace PJ, Zolotukhin S (2003) Sustained peripheral expression of transgene adiponectin offsets the development of diet-induced obesity in rats. Proc Natl Acad Sci U S A 100:14217-14222.

Smith AD, Brands MW, Wang MH, Dorrance AM (2006) Obesityinduced hypertension develops in young rats independently of the renin-angiotensin-aldosterone system. Exp Biol Med (Maywood) 231:282-287.

Soltis RP, DiMicco JA (1991a) GABAA and excitatory amino acid receptors in dorsomedial hypothalamus and heart rate in rats. Am J Physiol 260:R13-R20.

Soltis RP, DiMicco JA (1991b) Interaction of hypothalamic GABAA and excitatory amino acid receptors controlling heart rate in rats. Am J Physiol 261:R427-R433.

Soltis RP, DiMicco JA (1992) Hypothalamic excitatory amino acid receptors mediate stress-induced tachycardia in rats. Am J Physiol 262:R689-R697.

Song Y, Park HJ, Kang SN, Jang SH, Lee SJ, Ko YG, Kim GS, Cho JH (2013) Blueberry peel extracts inhibit adipogenesis in 3T3-L1 cells and reduce high-fat diet-induced obesity. PLoS One 8:e69925.

Stephens DN (1980) Does the Lee obesity index measure general obesity? Physiol Behav 25:313-315.

Stotz-Potter EH, Morin SM, DiMicco JA (1996a) Effect of microinjection of muscimol into the dorsomedial or paraventricular hypothalamic nucleus on air stress-induced neuroendocrine and cardiovascular changes in rats. Brain Res 742:219-224.

Stotz-Potter EH, Willis LR, DiMicco JA (1996b) Muscimol acts in dorsomedial but not paraventricular hypothalamic nucleus to suppress cardiovascular effects of stress. J Neurosci 16:1173-1179.

Tritos NA, Elmquist JK, Mastaitis JW, Flier JS, Maratos-Flier E (1998) Characterization of expression of hypothalamic appetiteregulating peptides in obese hyperleptinemic brown adipose tissue-deficient (uncoupling protein-promoter-driven diphtheria toxin A) mice. Endocrinology 139:4634-4641.

Walker MW, Ewald DA, Perney TM, Miller RJ (1988) Neuropeptide Y modulates neurotransmitter release and $\mathrm{Ca} 2+$ currents in rat sensory neurons. J Neurosci 8:2438-2446.

Xin X, Storlien LH, Huang XF (2000) Hypothalamic c-fos-like immunoreactivity in high-fat diet-induced obese and resistant mice. Brain Res Bull 52:235-242. 